ABSTRACT: The hepatic porphyrias are a group of rare metabolic disorders characterized by enzymatic defects in the biosynthesis of heme, a metalloporphyrin that is the principal product of porphyrin metabolism. The hepatic porphyrias are genetically transmitted as autosomal-dominant disorders with variable expression that produce a particularly severe form of neuropathy. Most medical students readily recognize acute attacks of porphyria when the classic triad of abdominal pain, psychosis, and neuropathy is present. Yet, porphyric neuropathy is a source of confusion in practice, and patients with porphyria rarely receive the correct diagnosis early in the course of the illness. Porphyric neuropathy is manifest by symptoms, signs, and cerebrospinal fluid abnormalities resembling acute Guillain-Barré syndrome. However, accompanying psychological features, a proximal predilection of asymmetric weakness, and electrodiagnostic findings indicative of an axonal polyradiculopathy or neuronopathy all suggest the diagnosis of porphyria. Confirmation of the diagnosis depends on use of appropriate laboratory studies. The underlying pathophysiology of porphyric neuropathy has not been established, but it may be related to direct neurotoxicity of elevated levels of $\delta$-aminolevulinic acid. The severity of the neuropathy and the availability of potential treatments, including avoidance of provocative factors, make identification important.

Muscle Nerve 30: 410-422, 2004

\title{
PORPHYRIC NEUROPATHY
}

\author{
JAMES W. ALBERS, MD, PhD, ${ }^{1,2}$ and JOHN K. FINK, MD ${ }^{1,3}$ \\ ${ }^{1}$ Department of Neurology, 1C325/0032 University Hospital, \\ University of Michigan Health System, 1500 East Medical Center Drive, \\ Ann Arbor, Michigan 48109-0032, USA \\ ${ }^{2}$ Neurobehavioral Toxicology Program, University of Michigan, \\ Ann Arbor, Michigan, USA \\ ${ }^{3}$ Geriatric Research Education and Clinical Center, \\ Ann Arbor Veterans Affairs Medical Center, Ann Arbor, Michigan, USA
}

Accepted 7 June 2004

Relatively distinct forms of peripheral neuropathy develop on occasion in association with certain types of porphyria. The term "porphyria" is used to designate a group of rare metabolic disorders characterized by enzymatic defects in the biosynthesis of porphyrinogens or in the transformation of porphyrinogens to heme, a metalloporphyrin that is the principal product of porphyrin metabolism. ${ }^{66}$ Heme acts as an oxygen carrier central to all biological aerobic reactions involving the transfer of oxygen to a substrate ${ }^{62}$ Heme is incorporated into various proteins, including hemoglobin and myoglobin, where it is essential for aerobic metabolism and adenosine triphosphate (ATP) production. As a prosthetic

\footnotetext{
Abbreviations: ADP, adenosine disphosphate; ALA, $\delta$-aminolevulinic acid Key words: nervous system; neuropathy; porphyria; porphyric neuropathy Correspondence to: J.W. Albers; e-mail: jwalbers@umich.edu

(C) 2004 Wiley Periodicals, Inc. This article is a US Government work and, as such, is in the public domain in the United States of America.

Published online 5 August 2004 in Wiley InterScience (www.interscience. wiley.com). DOI 10.1002/mus.20137
}

group of the hepatic $\mathrm{P} 450$ microsomal cytochromes, heme participates in the mitochondrial electron transport chain responsible for the metabolism of many substances, including numerous drugs. Many of these same substances precipitate acute attacks of porphyria. Hepatic synthesis of microsomal cytochromes in the mitochondrial electron transport chain can be induced by as much as $40-50$-fold by many common medications, including barbiturates. ${ }^{8,78}$ During activation of the cytochrome P450 system, intracellular heme is incorporated into the hepatic cytochromes, depleting reserves. As the heme concentration decreases, $\delta$-aminolevulinic acid (ALA) synthase is disinhibited and the porphyrin metabolic pathway is activated. During times of increased heme synthesis, patients with porphyria overproduce certain heme precursors, some of which may be neurotoxic when present in excess amounts. The specific enzyme deficiency predicts which heme precursors accumulate excessively in tissues and body fluids. These excessive heme pre- 
cursors are excreted in the urine, where they undergo oxidation into pigmented porphyrins, and feces. In the urine, pigmented porphyrins produce the dark red discoloration which is a characteristic of some porphyrias. ${ }^{29}$ The metabolic defects, which may at times result in excessive accumulation of porphyrin precursors or porphyrins, produce several clinical syndromes. Some of these syndromes include the development of neuropathy, the focus of this review.

\section{HISTORICAL REVIEW}

One of the first descriptions of porphyria is believed to be that of Ranking and Pardington near the end of the 19th century. ${ }^{74}$ Shortly thereafter, Dobrschansky recognized that barbiturates could produce attacks of porphyria in susceptible individuals, a remarkable observation for the time. ${ }^{21}$ Gunther, in 1911, described the constellation of skin photosensitivity, abdominal pain, constipation, and vomiting, which he attributed to a hereditary "congenital hematoporphyria." 36 The descriptor "porphyria" is related to the characteristic color of porphyrins. Porphyria is derived from porphuros, which is Greek for purple. The descriptor is a misnomer for the underlying metabolic disorder because, depending on the specific enzymatic defect, colorless porphyrin precursors are produced and excreted in excess, not pigmented porphyrins. Porphyria is the result of impaired porphyrinogen formation or impaired heme biosynthesis, not excess porphyrin production. ${ }^{26,78}$ During an attack, freshly voided urine may initially be colorless. However, porphyrin precursors are oxidized to pigmented porphyrins in the bladder or after voiding, when the urine is in the open air and ambient light. ${ }^{26,78}$ This reaction likely accounts for tales of astute clinicians who diagnosed porphyria after observing discolored urine that had been placed in a transparent container on a windowsill. In 1937, Waldenstrom treated the urine of known porphyria patients and their relatives with Ehrlich's reagent ( $p$-dimethylaminobenzaldehyde), causing it to turn red in the presence of excess porphyrin precursors. Using this test, he was able to predict which of the patient's relatives could safely ingest barbiturates based on whose urine reacted with Ehrlich's reagent. He proposed the dominant mode of inheritance that is now established.

In retrospect, the porphyrias have an intriguing history, romanticized by association with royalty, legends of vampires and werewolves, and famous individuals. MacAlpine and Hunter proposed that the "insanity" of George William Frederick (George III,
King of England from 1760 to 1811) was attributed to porphyria, accounting for his repeated episodes of madness, abdominal pain, constipation, muscle weakness, and dark urine..$^{5,51,53}$ They presented the argument that King George III signed the Stamp Act during one such episode, thereby provoking the American Revolution. MacAlpine and Hunter also identified other royal family members who could be affected and described two who were subjected to diagnostic evaluations, the results of which supported the diagnosis of porphyria. ${ }^{52,53}$ MacAlpine and Hunter speculated that the illness of King George III could be traced to Mary, Queen of Scots, and they coined the term "royal malady" to describe the possible presence of porphyria within the genes of royalty. ${ }^{53}$ Moore and colleagues suggested that legends of werewolves and vampires may have resulted from the existence of individuals with cutaneous porphyrias. ${ }^{62}$ Such individuals have deposition of porphyrins in the skin and severe photosensitivity. They exhibit an aversion to light, because light exposure produces fragility of the skin, bullae, and hypertrichosis. ${ }^{12,76}$ Some have speculated that Vincent van Gogh may have had porphyria, accounting for his episodic abdominal pain, seizures, and hallucinations, which may have influenced his paintings. ${ }^{50}$

\section{PORPHYRIN METABOLISM}

Biosynthesis of heme (Fig. 1), the principal product of porphyrin metabolism, begins in the mitochondria, where succinyl coenzyme A combines with glycine to form ALA. ${ }^{89}$ This reaction is catalyzed by the enzyme ALA synthase, the rate-limiting step in heme formation. ${ }^{67}$ ALA synthase is inhibited by the endproduct heme, in a form of direct negative feedback. ALA synthase is also inhibited by pyridoxine deficiency, as it is pyridoxine-dependent. ALA enters the cytoplasm where the next steps in the biosynthesis of heme occur. The first step involves conversion of two ALA molecules into the basic pyrrole ring, porphobilinogen, a reaction that is catalyzed by ALA dehydratase. Four porphobilinogen molecules are condensed to form uroporphyrinogen, the initial tetrapyrrole ring. Uroporphyrinogen synthase and cosynthase, via an unstable intermediate, catalyze this step. Uroporphyrinogen decarboxylase converts uroporphyrinogen into coproporphyrinogen. Coproporphyrinogen enters the mitochondria where it is converted sequentially into protoporphyrinogen and protoporphyrin IX, reactions catalyzed by coproporphyrinogen oxidase and protoporphyrinogen oxidase, respectively. The final step in the biosynthesis of heme is the addition of iron by ferrochelatase. 


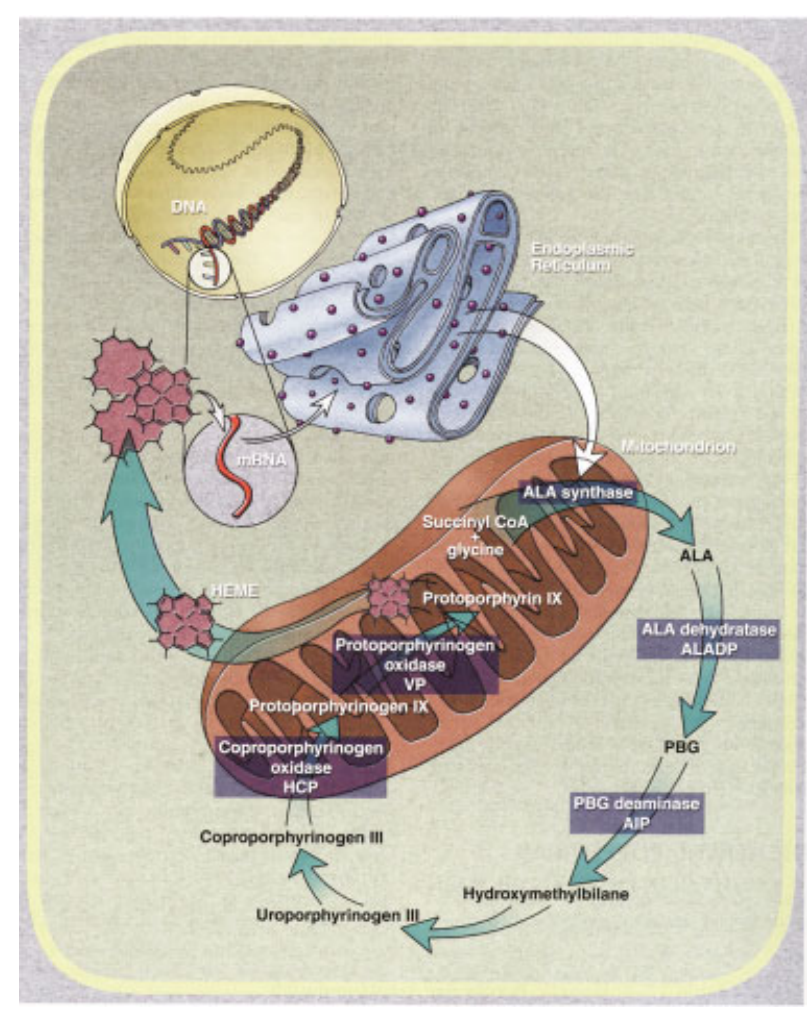

FIGURE 1. Heme biosynthesis from glycine and succinyl coenzyme $A$ to heme, demonstrating the intracellular free heme pool and its role in the feedback control of heme biosynthesis. ALA, $\delta$-aminovulinic acid; PBG, porphobilinogen; AIP, acute intermittent porphyria; $\mathrm{HCP}$, hereditary coproporphyria; VP, variegate porphria. (Reprinted from Albers, ${ }^{2}$ with permission.)

\section{CLASSIFICATION AND LABORATORY FINDINGS}

The different forms of porphyria are classified on the bases of which tissues they preferentially affect or where the metabolic defect occurs. ${ }^{66,81}$ The erythropoietic porphyrias include a group of disorders that influence the production of red blood cells. These porphyrias are manifest primarily by skin sensitivity. They are not associated with adverse neurological consequences and they will not be discussed in this review. The acute hepatic porphyrias are so named because the deficient biosynthetic step occurs in the liver. The acute hepatic porphyrias consist of ALA dehydratase deficiency, acute intermittent porphyria, hereditary coproporphyria, variegate porphyria, and porphyria cutanea tarda. ${ }^{35,66}$ All of the hepatic porphyrias are associated with variable extrahepatic gastrointestinal and neuropsychiatric manifestations, including neuropathy, except for porphyria cutanea tarda. Porphyria cutanea tarda does not produce neurological manifestations and will not be reviewed. ALA dehydratase deficiency is the least common of the hepatic porphyries. It is the only porphyric neuropathy to present in infancy, and the only autosomal-recessive hepatic porphyria. ${ }^{94}$

The hepatic porphyrias can be classified using the results of biochemical laboratory analyses. Acute attacks of porphyria are associated with increased production of heme precursors. The specific enzyme deficiency associated with the various hepatic porphyrias predicts which heme precursors will be excreted in excess, as metabolites upstream of the enzymatic defect accumulate. ${ }^{35}$ The initial step in the evaluation of patients with suspected porphyric neuropathy is to establish an abnormal excretion pattern of urine and fecal porphyrins. Qualitative random screening tests can be performed on the urine to identify elevated porphobilinogen levels. This may be followed by a 24-hour collection to assess porphyrin levels. The complete laboratory evaluation requires quantitative analysis of ALA, porphobilinogen, and porphyrins in blood, urine, and feces, and analyses of enzyme activities for specific enzyme deficiencies of the heme-forming system (Table 1). ${ }^{27,52}$ The interpretation of laboratory results is at times confusing, in part because of nonenzymatic metabolism of porphyrin precursors in the bladder and because the analyses employed to identify abnormal levels of heme precursors oxidize all porphyrinogens to porphyrins. The distinction between hereditary coproporphyria and variegate porphyria is determined by the relative amounts of coproporphyrin and protoporphyrin present, not by some absolute threshold amount. The difficulty in distinguishing among hereditary coproporphyria and variegate porphyria is further complicated by nonenzymatic oxidation of heme precursors along the heme pathway and by the existence of patients who have combined enzymatic defects. ${ }^{12}$

In acute attacks, heme metabolites are excreted in the urine and feces in excess of the small residual amounts normally excreted each day. ${ }^{52,90}$ The quantitative determination of excreted heme precursors and their metabolites in 24-hour collections of urine and feces is used to secure the diagnosis, and to help establish which form of porphyria explains the excess excretion. For example, acute intermittent porphyria, the most common of the hepatic porphyrias, occurs as the result of a partial deficiency or decreased activity of porphobilinogen deaminase. ${ }^{67}$ During an attack of acute intermittent porphyria, urinary excretion levels of ALA and porphobilinogen are markedly elevated. In contrast, hereditary coproporphyria results from decreased activity of coproporphyrinogen oxidase. This deficiency produces marked elevations of urinary ALA and porphobilinogen during an attack. In distinction from 


\begin{tabular}{lccc}
\hline \multicolumn{2}{c}{ Table 1. Characteristic patterns of abnormal levels of heme precursors in the urine and feces during an attack of hepatic porphyria. ${ }^{2}$} \\
\hline Type & Enzyme deficiency & Urine ${ }^{\star}$ & Feces $^{\dagger}$ \\
\hline ALA dehydratase deficiency & ALA dehydratase & $\uparrow$ ALA, Copro & Normal \\
Acute intermittent & Hydroxymethylbilane (also & $\uparrow$ ALA, PBG, Uro & Normal \\
& called PBG deaminase) & $\uparrow$ ALA, PBG, Uro, Copro & $\uparrow$ Copro $>$ Proto \\
Hereditary coproporphyria & Copro oxidase & $\uparrow$ ALA, PBG, Uro, Copro & $\uparrow$ Proto $>$ Copro \\
Variegate porphyria & Proto oxidase &
\end{tabular}

ALA, $\delta$-aminolevulinic acid; Copro, coproporphyrinogen; PBG, porphobilinogen; Proto, protoporphyrinogen; Uro, uroporphyrinogen.

*Autoxidized in the bladder by nonenzymatic oxidation and during laboratory testing to all porphyrin heme precursors results in confusing profile that may vary.

${ }^{\dagger}$ Fecal porphyrins provide the best means of distinguishing between hereditary coproporphyria and variegate porphyria.

acute intermittent porphyria, coproporphyrinogen excretion levels are increased in urine and feces. Variegate porphyria is associated with decreased protoporphyrinogen oxidase activity, ${ }^{67}$ which results in increased urinary excretion of ALA, porphobilinogen, and coproporphyrinogen during an attack. In the feces, there may be mild elevation of coproporphyrinogen and marked elevation of protoporphyrinogen. Nevertheless, the laboratory abnormalities, which remain the primary basis for diagnosis, ${ }^{35}$ frequently overlap among the different porphyrias, and the specific type of porphyria cannot always be accurately determined. For a given patient with a hepatic porphyria, heme precursors often are excreted in urine and stool in normal amounts between attacks. When elevated levels are found, they may be present in confusing patterns. ${ }^{23}$

Enzyme determinations can be used to identify and distinguish among the hepatic porphyrias, although results also may be misleading. ${ }^{35}$ The activities of porphobilinogen deaminase (acute intermittent porphyria) and coproporphyrinogen oxidase (hereditary coproporphyria) can be measured in erythrocytes, as the same pathway is present in the erythropoietic line. It has been estimated that about $80 \%$ of patients with acute intermittent porphyria have abnormal enzyme activity. ${ }^{63}$ Enzymes activity also may be used to identify patients who are in the latent stage of the disease when evaluated, as well as to identify asymptomatic relatives who possess the genetic defect. ${ }^{72}$ Among patients with variegate porphyria, there is a decreased protoporphyrinogen oxidase activity measured in cultured lymphoblasts. ${ }^{59}$ Enzyme activity among patients with variegate porphyria averages about $50 \%$ of referent values. ${ }^{59}$

Although a diagnosis of porphyria is unlikely if excretion levels of heme precursors are normal during an acute episode, not all patients who have abnormal levels have porphyria. Most patients referred with a presumptive diagnosis of "porphyria" have disorders associated with mild, nonspecific increases in porphyrin excretion (secondary porphyrurias). ${ }^{9}$
Many conditions unrelated to the hepatic porphyrias, including, for example, diabetes mellitus, liver disease, and iron-deficiency anemia, are associated with overproduction and increased excretion of porphyrin precursors. In addition, porphyrin precursors may be overproduced and overexcreted in relation to some particular substance, another form of secondary porphyruria termed "intoxication" porphyria. ${ }^{8,22}$ Excessive ingestion of ethanol results in an accumulation of iron, which inhibits uroporphyrinogen decarboxylase and thereby interferes with porphyrin metabolism. ${ }^{18}$ Similarly, numerous medications induce the hepatic cytochrome P450 system and produce modest elevations of urinary coproporphyrinogen among normal individuals. ${ }^{26}$ There are no clinical manifestations associated with the secondary or toxic porphyrurias. Correction of the underlying problem or removal from exposure to the offending substance results in a return to normal porphyrin levels. ${ }^{97}$ However, additional laboratory evaluations, including measurement of excretion of heme precursors in feces, may be required to distinguish these patients from those with hereditary coproporphyria. ${ }^{8}$

\section{GENETIC FEATURES}

The vast majority of inherited enzyme abnormalities (e.g., Tay-Sachs disease and phenylketonuria) are transmitted as autosomal-recessive traits. For such disorders, a pathogenic threshold of biochemical disturbance is crossed only when both alleles are disturbed (by homozygous or compound heterozygous mutations). It is not uncommon in such autosomal-recessive enzyme disorders for "residual enzyme function" to be less than $5 \%$. Further, the vast majority of inherited enzyme deficiencies are asymptomatic in the heterozygous state. In contrast, three of the four forms of hepatic porphyria associated with neuropathy (acute intermittent porphyria, variegate porphyria, and hereditary coproporphyria) are unusual in that they are inherited enzyme disor- 
ders that are transmitted as autosomal-dominant traits. Apparently, for these forms of porphyria, even $50 \%$ residual enzyme activity is insufficient to prevent neuropathic levels of the specific heme-pathway intermediates.

There have been considerable advances in our understanding of the molecular basis of porphyrias. Genes responsible for ALA dehydratase-deficient porphyria (5 ALA dehydratase), ${ }^{38}$ acute intermittent porphyria (hydroxymethylbilane synthase, also called porphobilinogen deaminase), ${ }^{14,32,42,84,86}$ hereditary coproporphyria (coproporphyrinogen oxidase), 15,31,48,55,85 and variegate porphyria (protoporphyrinogen oxidase) ${ }^{19,58,96}$ have been mapped, cloned, and disease-specific mutations identified. ${ }^{11,14,32,54,65,73,77,82,84,86,92,95}$ Still, for the vast majority of subjects, laboratory diagnosis is based on biochemical analysis of the pattern of excess porphyrin and porphyrin precursors in plasma and urinary concentrations. Nonetheless, definitive diagnosis of a particular type of porphyria can be achieved by demonstration of a disease-specific mutation in the causative gene. Such studies are important because there may be significant overlap between highheterozygote and low-normal values. ${ }^{17}$

As noted previously, ALA dehydratase-deficient porphyria is different from the other forms of acute hepatic porphyria associated with neuropathy because it is transmitted as an autosomal-recessive trait. Although ALA dehydratase-deficient porphyria is rare worldwide, the frequency of carriers in Sweden was estimated to be about $2 \% .{ }^{17}$ Desnick and associates emphasized that ALA dehydratase inhibition by lead, styrene, and succinylacetone produced clinical and laboratory signs similar to those of acute porphyria. ${ }^{17}$ For this reason, they recommend confirming the diagnosis of ALA dehydratase-deficient porphyria with adenosine diphosphate mutation analysis. Five point mutations and a two-base deletion of the ALA dehydratase gene have been reported. ${ }^{17}$ Prenatal diagnosis of ALA dehydratase-deficient porphyria is possible (although not yet reported) by analysis of ALA dehydratase enzyme activity or gene mutation in a chorionic villus sample or amniocytes. ${ }^{17}$

Acute intermittent porphyria, probably the most common type of genetic porphyria, ${ }^{41}$ occurs in all ethnic groups but is most common in Scandinavia, Britain, and Ireland. ${ }^{17}$ The prevalence of acute intermittent porphyria is estimated to be of the order of 1 in 10,000 to 1 in 100,000 among the white population. ${ }^{97}$ Acute intermittent porphyria is due to mutations in the hydroxymethylbilane synthase (porphobilinogen deaminase) gene. ${ }^{17,41}$ The vast major- ity of the more than 160 reported mutations are restricted to the family in which they were discovered. ${ }^{14,32-34,42,83,84,86}$ Two distinct mRNAs of porphobilinogen deaminase are produced through alternative splicing, one of which is present only in erythroid cells, whereas the other is expressed in all tissues. ${ }^{33,34}$ Exon 1 is spliced out of the mRNA of the erythroid enzyme; mutations involving this $5^{\prime}$ region may lead to a false-positive erythrocyte assay for porphobilinogen deaminase. Molecular defects also occur in other portions of the gene, producing abnormal hepatic and erythroid isoforms of porphobilinogen deaminase.

It is important to note that approximately $90 \%$ of subjects with hydroxymethylbilane synthase/porphobilinogen deaminase gene mutations are clinically asymptomatic and do not have laboratory evidence of acute intermittent porphyria. ${ }^{37,41,78}$ This demonstrates the important role of other genes and environmental factors, including diet, medications, nutrition, and physical activity, in causing episodes of acute intermittent porphyria, and underscores the need to diagnose acute intermittent porphyria by a combination of clinical and biochemical laboratory findings rather than by the presence of hydroxymethylbilane synthase/porphobilinogen deaminase gene mutation alone.

Hereditary coproporphyria is due to mutations in the coproporphyrinogen oxidase gene. Although usually transmitted as an autosomal-dominant disorder, homozygous affected subjects have been reported. ${ }^{17}$ Many different coproporphyrinogen oxidase mutations have been identified, and, as with other types of porphyria, these mutations are almost always unique to the family in which they were discovered.

Variegate porphyria is due to mutations in the protoporphyrinogen oxidase gene. Although usually an uncommon form of porphyria, variegate porphyria has a high prevalence in South Africa, where it is estimated that $0.3 \%$ of whites have variegate porphyria. ${ }^{5}$ Kirsch et al. attributed the high prevalence of variegate porphyria in South African whites to a Dutch immigrant in $1688 .^{13,17,24,43}$ One missense mutation (R59W) has been identified as the common mutation in South African variegate porphyria subjects of Dutch descent. ${ }^{17}$ Many other mutations have also been identified and are usually restricted to the family in which they were discovered. Rare subjects with homozygous mutations have been identified. Such subjects have specific protoporphyrinogen oxidase mutations, which result in greater residual enzyme activity than those causing autosomal-dominant variegate porphyria. 


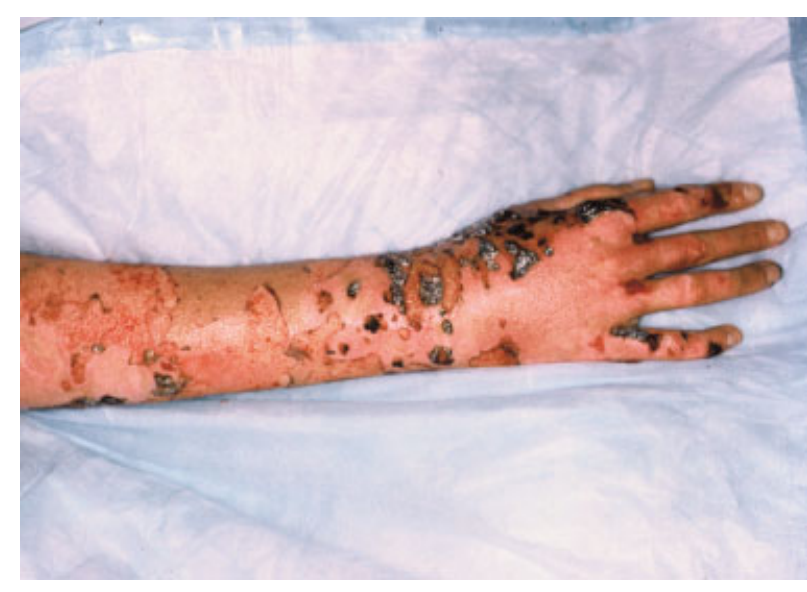

FIGURE 2. Photograph taken during an acute episode of quadriparesis, respiratory failure, and photodistribution skin lesions. The skin lesions were characterized by mechanical fragility, multiple blisters and bullae, and rupture of bullae into open sores. The patient had biochemical evidence of coproporphyria, although a diagnosis of variegate porphyria could not be completely excluded. (Reprinted from Albers, ${ }^{2}$ with permission.)

\section{Clinical features}

Porphyric neuropathy occurs in association with other features of an acute attack of hepatic porphyria, not in isolation. Recognition of those more general systemic features is important in considering the diagnosis of porphyria.

General Features. The acute hepatic porphyrias, with the exception of porphyria cutanea tarda, exhibit similar systemic and neurological involvement as prominent features of their clinical course. The primary difference between the three disorders is the presence of skin lesions among patients with hereditary coproporphyria and variegate porphyria but not with acute intermittent porphyria. The skin lesions are related to deposition of photosensitive porphyrins in the skin, producing bullae, increased fragility, and hypertrichosis (Fig. 2).2,12,76 Neurological involvement includes central and peripheral nervous system manifestations, typically as part of a discrete episode during an acute attack. The neurological features do not distinguish among the hepatic porphyrias. Although the porphyrias are a source of confusion for clinicians, this condition is one that is readily recognized when presenting with the classic triad of abdominal pain, psychosis, and neuropathy. In practice, however, patients with porphyria rarely receive the correct diagnosis early in the course of the illness, perhaps because of the rarity of the disease and the sometimes vague clinical presentations. Nevertheless, most attacks of porphyria follow a predictive course. Attacks may be precip- itated or promoted by many factors, the most important being medications. ${ }^{60}$ Other situations that affect porphyrin metabolism may exacerbate an attack. For example, starvation states with reduced glucose concentration are important precipitants because glucose inhibits ALA synthase. ${ }^{97}$ Hormone levels also affect heme metabolism, ${ }^{97}$ and progesterone, estrogen, and testosterone all activate ALA synthase, likely explaining why attacks of porphyria are rare prior to puberty, ${ }^{97}$ and perhaps explaining why attacks are more common in women. Despite the recognition of numerous potential precipitants, the acute precipitating event is only identified on occasion.

Attacks of porphyria typically begin with abdominal pain, followed by psychiatric problems and other central nervous system manifestations. The abdominal pain is usually severe and the presentation dramatic, reflecting poorly localized visceral pain with few physical findings other than a resting tachycardia and possibly elevated blood pressure. Constipation is usually present, often with nausea with vomiting. The abdominal pain is sometimes sufficient to require pain medications or to result in exploratory surgery requiring anesthesia, both forms of treatment that may sustain or exacerbate an attack. ${ }^{76}$ The mental status and psychiatric manifestations that develop, either in association with the abdominal pain or soon afterward, are nonspecific. They include restlessness, insomnia, and agitation followed by varying degrees of neurotic or hysterical behaviors. ${ }^{76}$ A diagnoses of somatization disorder or conversion reaction frequently is considered, based on the psychiatric features and unremarkable abdominal examination. These behaviors may result in sedation with barbiturates or similar medications. Barbiturates, of course, are among those medications that promote increased heme synthesis and a resultant increase in heme precursors. Some patients develop mental status changes, delirium, and hallucinations, and occasionally become comatose. ${ }^{79,87}$ Generalized tonic-clonic or partial complex seizures occur commonly during an acute porphyric attack. The central nervous system findings resemble a posterior leukoencephalopathy, and the most common focal deficit is cortical blindness secondary to occipital lobe infarctions. ${ }^{44}$

Neuropathy. The incidence of neuropathy among patients with porphyria is unknown. Estimates of the frequency of neuropathy, based on information derived from patients diagnosed with porphyria (presumably because of porphyric attacks), suggest that $10-40 \%$ develop neuropathy. ${ }^{3,88}$ These percentages do not account for the substantial number of asymp- 
tomatic carriers (based on the known autosomaldominant transmission) or those patients who develop porphyric neuropathy without being diagnosed with porphyria. Although it is believed that many patients with suspected Guillain-Barré syndrome actually have porphyric neuropathy, no patient among the 450 patients screened for the North American study of plasmapheresis and acute Guillain-Barré syndrome was excluded because of porphyria. ${ }^{93}$

Porphyric neuropathy likely consists of a combined autonomic neuropathy and a peripheral neuropathy. It is generally thought that the abdominal pain that heralds the onset of a porphyric attack reflects an autonomic neuropathy producing decreased gastric motility, constipation, and pseudoobstruction. Other signs of autonomic neuropathy include a resting tachycardia. Symptomatic orthostatic hypotension may be present, but labile hypertension is a more common finding. Episodic diaphoresis may occur. ${ }^{87}$ Rare patients develop urinary and rectal sphincter incontinence. ${ }^{30}$ Autonomic function testing may confirm severe autonomic dysfunction during the attacks, ${ }^{45,91}$ and porphyric autonomic neuropathy may develop in isolation. ${ }^{91}$

Peripheral neuropathy, which can be severe and life-threatening, develops after the onset of abdominal pain, psychiatric abnormalities, and other central nervous system manifestations. ${ }^{75}$ Among a series of patients with porphyria, neuropathy developed 3-75 days after the onset of the abdominal pain. ${ }^{76}$ In another series, $80 \%$ of patients who developed porphyric neuropathy did so within 1 month of developing abdominal pain. ${ }^{75}$ In general, once neuropathy appears, it progresses to a maximum deficit over approximately 1 month. ${ }^{78}$ At the nadir of illness, there may be total quadriplegia and respiratory insufficiency requiring ventilator support.

Several forms of porphyric neuropathy have been reported, but the typical neuropathy is generally considered to be a primary motor neuropathy, ${ }^{49}$ characterized clinically by weakness, areflexia, and sensory symptoms with or without demonstrable sensory loss. ${ }^{3,78,89}$ Laboratory abnormalities include evidence of elevated total protein and normal cell count in the cerebrospinal fluid. In the context of an antecedent gastrointestinal illness, the combination of an acute-onset motor neuropathy and areflexia, respiratory insufficiency, and elevated cerebrospinal fluid protein without pleocytosis suggest a diagnosis of Guillain-Barré syndrome. Not surprisingly, the diagnosis of porphyric neuropathy at times is not considered until the second attack of neuropathy, because recurrent Guillain-Barré syndrome is un- common. Other features of porphyric neuropathy, including labile hypertension and tachycardia suggestive of an autonomic neuropathy, also are associated with the Guillain-Barré syndrome. Because of the striking similarities between porphyric neuropathy and Guillain-Barré syndrome, urine porphyrins are examined routinely in clinical studies of inflammatory neuropathy. ${ }^{93}$

One apparent feature of porphyric neuropathy that is atypical of most other forms of neuropathy is the distribution of abnormality. In one series, about $50 \%$ of patients with porphyric neuropathy experienced onset in the arms, and $80 \%$ had greatest involvement in the proximal muscles. ${ }^{75}$ One-third of the patients had onset in the legs; weakness was greatest proximally in about $50 \%$. The remaining patients developed onset of weakness simultaneously in the arms and legs. Asymmetric weakness was a common finding. In the same series of patients with porphyric neuropathy, a minority reported paresthesias and sensory loss in a stocking-and-glove distribution or a proximal "bathing suit" distribution. ${ }^{75}$

In addition to Guillain-Barré syndrome, other disorders producing a combination of symptoms and signs similar to those of porphyric neuropathy include vasculitis, heavy metal intoxication, and poliomyelitis. ${ }^{49}$ Vasculitic neuropathy is usually asymmetric at onset, presenting as mononeuritis multiplex. Laboratory evaluation for evidence of systemic vasculitis is helpful if positive, but peripheral nerve biopsy may be required to establish the diagnosis. Some reports of lead neuropathy resemble those of porphyric neuropathy. As with porphyria, the neuropathy associated with lead intoxication is thought to have an acute onset, involves motor nerve fibers more than sensory fibers, shows a multifocal distribution, and involves the arms preferentially, often in a proximal and asymmetric manner. Lead neuropathy also has been associated with abnormalities in the heme metabolic pathway and with abnormal excretion of heme precursors. The disruption of heme synthesis by lead is believed to contribute to the syndrome of lead toxicity, including the peripheral neuropathy. ${ }^{18}$ Lead intoxication usually is suspected by the clinical presentation and documented by an elevated serum lead level. ${ }^{78}$ Whether lead neuropathy is identical to porphyric neuropathy is unclear, as is the possibility that lead intoxication simply precipitates porphyric neuropathy among susceptible individuals. Acute lead intoxication interrupts later stages of porphyrin metabolism involving the formation of porphobilinogen. ${ }^{80}$ In lead neuropathy, increased urinary excretion of ALA and 
coproporphyrin are thought to be a consequence of ALA dehydratase inhibition. ${ }^{62}$

The prognosis for an attack of acute hepatic porphyric is generally good, with rapid resolution of abdominal pain, autonomic symptoms, and central nervous system manifestations once the attack is aborted. The neuropathy resolves much more slowly, and recovery from the neuropathy depends on the extent and magnitude of axonal degeneration. Recovery usually occurs over many months, often with incomplete return of motor function. After repeated attacks, cumulative deficits occur, as regeneration may be incomplete, producing fixed weakness and atrophy. The long-term prognosis depends on the ability to prevent recurrent porphyric attacks with prophylactic measures.

\section{ELECTROPHYSIOLOGICAL FINDINGS}

There are few electrodiagnostic evaluations of groups of patients with confirmed porphyric neuropathy. Most reports describe patients with porphyric neuropathy due to acute intermittent porphyria, the most common hepatic porphyria in the USA. However, despite the variable findings even among reports of neuropathy in acute intermittent porphyria, ${ }^{28,56,64,99}$ there is no firm evidence to suggest that the neuropathies differ among the different forms of hepatic porphyrias. More likely, differences in interpretation reflect when the evaluations were performed in relation to onset of neuropathy. Despite these limitations, electrophysiological results have been important in extending understanding of the pathophysiology of porphyric neuropathy. Electrodiagnostic testing is also important in the evaluation of the individual patient thought to have porphyric neuropathy, or, more importantly, acute GuillainBarré syndrome. This is because the diagnosis of porphyria may not be considered and the appropriate laboratory evaluations requested until the electrodiagnostic results appear atypical for GuillainBarré syndrome. Although there are no nerve conduction study or needle electromyography findings pathognomonic for porphyric neuropathy, the distribution and type of abnormality will sometimes suggest the diagnosis.

A retrospective review of patients who developed an acute weakness ultimately attributed to acute intermittent porphyria indicated that the electrodiagnostic abnormalities were best explained by an acute axonal neuropathy. ${ }^{3}$ Motor responses were generally of low amplitude, but conduction velocities and distal latencies recorded during the initial phase of the neuropathy were normal or only slightly abnormal.
The magnitude of conduction slowing was consistent with the degree of axonal degeneration or with loss of the fastest conducting motor fibers. No patient showed evidence of partial conduction block, and abnormal temporal dispersion of motor responses was not seen. ${ }^{3}$ At times, the same nerves showing motor abnormalities demonstrated relative or complete sparing of sensory function. Needle electromyography demonstrated prominent fibrillation potentials within several weeks of onset. The abnormalities were most prominent in proximal muscles, and sometimes more prominent in the arms than legs, a finding consistent with the clinical observations. Involvement was often multifocal, with relative sparing of some muscles immediately adjacent to other muscles that showed profound abnormalities. During the first few weeks of weakness, there were no motor unit abnormalities aside from reduced recruitment. Patients studied during the recovery phase showed evidence of ongoing reinnervation, characterized by high-amplitude, long-duration, polyphasic motor units. ${ }^{3}$ The electrophysiological features of the porphyric neuropathy were characterized as an acute axonal neuropathy or neuronopathy with variable amounts (none to severe) of sensory axon involvement. ${ }^{3}$ Importantly, the findings were not those of an acquired demyelinating neuropathy, and therefore atypical of those usually obtained in Guillain-Barré syndrome. A small percentage of patients with Guillain-Barré syndrome have an axonal form of neuropathy, and the findings are indistinguishable from those of porphyric neuropathy.

There also are reports of patients demonstrating small-amplitude, rapidly recruited motor units in proximal muscles. ${ }^{5}$ Although these findings are suggestive of a proximal porphyric myopathy, the "myopathic" motor units may represent selective involvement of the terminal axons of motor units, possibly due to failure of conduction or a functional impairment of neuromuscular transmission. Electrophysiological studies performed on patients with acute intermittent porphyria long after recovery from an acute attack of neuropathy indicate that most patients recover completely, but a small percentage continue to show evidence of a chronic neuropathy. 28

\section{PATHOLOGY AND PATHOPHYSIOLOGY}

The most consistent neuropathological feature of porphyric neuropathy is axonal loss with wallerian degeneration. ${ }^{16}$ Patchy areas of demyelination occur in association with axonal disruption and, infre- 
quently, isolated demyelination. ${ }^{16}$ Pure sensory nerves are frequently spared. Anterior horn cells demonstrate central chromatolysis, consistent with proximal axonal damage. On occasion, dorsal root ganglion cells also show central chromatolysis. The combined findings are consistent with the clinical presentation of a predominantly motor neuropathy of the axonal type. The findings suggestive of demyelination likely represent secondary demyelination due to axonal degeneration. ${ }^{97}$ None of the changes is specific, and a diagnosis of porphyric neuropathy cannot be established by nerve biopsy.

The mechanism by which a defect in heme metabolism produces neuropathy is unknown. Many of the hypothesis were proposed to explain central nervous system mechanisms, but most are, nonetheless, relevant to neuropathy. One hypothesis proposes that the metabolic abnormality in the heme pathway is sufficiently severe to result in heme deficiency. Heme is an essential component of the mitochondrial electron transport chain and critical to aerobic metabolism and adenosine triphosphate (ATP) production. Fast axonal transport is highly energydependent, and diminished ATP availability could disrupt this process and result in axonal death. This mechanism is not unique to porphyria, however. In opposition to this hypothesis, the intraneuronal heme pool should not diminish during an acute attack of hepatic porphyria, because there is little cytochrome $\mathrm{P} 450$ activity in the nervous system and ALA synthase should not be induced. ${ }^{70}$ Neuronal aerobic metabolism therefore should not be compromised. ${ }^{68}$ Also, other conditions that impair heme synthesis, such as iron deficiency, are not known to produce similar syndromes. ${ }^{7}$ Another hypothesis is that a reduced hepatic heme pool impairs metabolism of substances known to precipitate porphyric attacks. The impaired metabolism results in excessive accumulation of the precipitant, thereby producing the clinical manifestations of porphyria, including a toxic neuropathy. This explanation seems unlikely, given the wide range of identified precipitants, which are unlikely to share a common neurotoxicity. Also, the neurotoxicity potential of the known precipitants among patients without porphyria is variable. An alternative hypothesis suggests that, during an attack, heme precursors and their metabolites increase to levels that are neurotoxic. It is well known that many substances, including some essential vitamins, are neurotoxic when present in a sufficient dose. There is no evidence that attacks occur without an elevation of heme precursors. ${ }^{7}$ Also, lead intoxication, ${ }^{98}$ which inhibits ALA dehy- dratase and causes accumulation of ALA, is thought to produce a neuropathy similar to that of porphyria.

If accumulation of heme precursors is important in the pathogenesis of porphyric neuropathy, the one precursor common to all the porphyrias is ALA (Table 1). ALA does not ordinarily cross the bloodbrain or blood-nerve barriers. However, during an attack, ALA appears in measurable quantities in the cerebrospinal fluid, an observation of uncertain importance. ${ }^{69}$ It remains uncertain how ALA produces neuronal or axonal damage in the peripheral nervous system. ${ }^{27}$ ALA is believed to be an endogenous source of reactive oxygen species that can produce oxidative damage to cell structures in general, and there is experimental evidence that ALA induces necrotic cell death of mouse astrocytes. ${ }^{40}$ The clinical distribution of weakness involving proximal more than distal muscles at onset of porphyric neuropathy has been attributed to possible retrograde axonal transport of some neurotoxic substance from the distal motor axon to the motor neuron. ${ }^{5}$ Access at the neuromuscular junction occurs because there is no blood-nerve barrier at this site. If the heme precursor is toxic to the neuron at the level of the cell body, neurons innervating proximal muscles would initially be affected in this model involving retrograde axonal transport, explaining the proximal predilection seen in porphyric neuropathy. ${ }^{5}$

\section{TREATMENT}

Specific treatment of porphyric neuropathy includes abortive and preventive therapies that treat the underlying condition, not the neuropathy directly. The first is treatment during the acute attack and the second is prophylactic treatment between attacks. Treatment during an attack can be further separated into symptomatic treatment and disease-modifying treatment directed at aborting the attack. The symptomatic and supportive treatments of an acute porphyric attack include management of the many systemic manifestations. These treatments have been reviewed elsewhere and will not be addressed in this review of porphyric neuropathy. ${ }^{89}$ Supportive treatment includes opiates for pain control, monitoring for and treatment of medical complications such as hypertension and hyponatremia, and monitoring of respiratory function. ${ }^{6}$ Many medications accentuate or precipitate acute attacks, particularly those that induce cytochrome P450 enzymes and therefore hepatic heme precursors. Medications should be used cautiously, selecting to the extent possible those believed to be safe in terms of accentuating porphyria. Table 2 lists several medications that are generally 
Table 2. Examples of medications and substances reported to be potentially safe, potentially unsafe, and unsafe for use in patients with hepatic porphyria. 1,2,4,25,97

\begin{tabular}{|c|c|c|}
\hline Potentially safe* & Potentially unsafe & Unsafe \\
\hline Acetaminophen & Agents inducing & Alcohol \\
\hline Acyclovir & cytochrome P450 & Barbiturates \\
\hline Amantadine & Alkylating agents & Calcium channel \\
\hline Aspirin & Clonidine & blockers \\
\hline Atropine & Chloroquine & Carbamazepine \\
\hline Beta blockers & Estrogens & Chloramphenicol \\
\hline Bromides & Erythromycin & Chlorpropamide \\
\hline Cimetidine & Hydralazine & Clonazepam \\
\hline Chloral hydrate & Ketamine & Danazol \\
\hline Chlorpromazine & Lidocaine & Ketamine \\
\hline Colchicine & Lidocaine & Dapsone \\
\hline Dopamine & Methyldopa & Ergots \\
\hline Fentanyl & Nalidixic acid & Felbamate \\
\hline Gabapentin & Nortryptyline & Griseofulvin \\
\hline Glucocorticoids & Pentazocine & Halothane \\
\hline Haloperidol & Phenoxybenzamine & Meprobamate \\
\hline Insulin & Rifampin & Phenytoin \\
\hline Narcotic analgesics & Spirolactone & Primidone \\
\hline Neostigmine & Theophylline & Progestins \\
\hline Procaine & & Succinamides \\
\hline Penicillin & & Sulfonamides \\
\hline Phenothiazines & & Theophylline \\
\hline Propofo & & Tolazamide \\
\hline IPropranolol & & Tolbutamide \\
\hline Reserpine & & Tranquilizers \\
\hline Serotonin reuptake & & Trimethadone \\
\hline inhibitors & & Valproic acid \\
\hline \multicolumn{3}{|l|}{ Streptomycin } \\
\hline \multicolumn{3}{|l|}{ Tetracycline } \\
\hline Vitamins & & \\
\hline
\end{tabular}

*Numerous medications are reported to precipitate acute attacks of porphyria and all medications should be used with caution, weighing the potential risk/benefit ratio, considering alternative treatment choices, and consulting current sources of drug information.

considered safe for use during attacks of acute porphyria. Because of the availability of new medications, as well as accumulating experience with older medications with regard to treatment of acute porphyria, it is important to consult current references before initiating treatments; for example, organizations such as the American Porphyria Foundation and the Welsh Medicines Information Centre, and other publications and sources that maintain updated information on the use of medications in porphyria. ${ }^{1,4,25}$

Patients with acute porphyric neuropathy, akin to patients with dysautonomia due to Guillain-Barré syndrome, may show dramatic or accentuated response to hypertensive medications, and treatment should begin at low doses using medications with a short half-life. ${ }^{46,61}$ The hypertension and tachycardia associated with acute porphyric neuropathy often respond to propranolol or related medications. Hy- dration is important as oral intake is often reduced. The syndrome of inappropriate antidiuretic hormone secretion occurs among patients with acute porphyria, and close attention to electrolytes is warranted with fluid management adjusted to maintain adequate hydration without inducing hyponatremia. ${ }^{6}$ Controlling the environment also is important. It is important to recognize the potential photosensitivity among patients with hereditary coproporphyria or variegate porphyria, particularly those patients admitted to an intensive care setting. Ideally the patient should be provided a dark room.

The primary treatment of porphyric neuropathy is directed at the underlying cause, recognizing that there is no treatment that will rapidly reverse a neuropathy cause by axonal degeneration. Maintaining an adequate carbohydrate load is standard therapy for a porphyric attack, because glucose inhibits ALA synthase, the rate-limiting step in heme synthesis. Patients who have satisfactory oral intake should maintain a minimum of $2500 \mathrm{kcal}$ per day, including at least 300-400 grams of carbohydrates plus adequate protein. ${ }^{9,46,61}$ Patients who are unable to maintain adequate oral intake require intravenous supplementation. If carbohydrate loading does not promptly relieve systemic symptoms of the acute attack, intravenous heme is indicated. ${ }^{9}$ Because heme is the major inhibitor of ALA synthase via feedback inhibition, ALA synthase activity is markedly reduced, as is the production of porphyrin metabolites, by hematin during an attack. ${ }^{10,20,47}$ Despite the known pharmacological effects, the clinical response to hematin treatment is controversial. However, most but not all trials have shown clinical benefit, ${ }^{57,71}$ although clinical improvement is difficult to fully assess in a relapsing and remitting illness of this type. Hematin is administered intravenously at a recommended dose of $4 \mathrm{mg} / \mathrm{kg}$ / day given once every 24 hours or in two divided doses each 12 hours for 4-14 days, depending upon response. ${ }^{46}$ After of a full course of hematin, a rebound increase in porphyrin levels may occur. Some patients show a similar rebound, sometimes sufficient to precipitate a second attack, after discontinuation of intravenous glucose during the initial recovery stage of the attack.

The treatment of the inducible porphyrias involves prophylaxis of attacks of porphyria. This is accomplished primarily by avoiding precipitating factors, to the extent possible. Some carriers of the abnormal genes associated with the hepatic porphyrias are vulnerable to a wide range of exogenous and endogenous factors. ${ }^{66}$ Included among these factors are medications, sex hormones, fasting, and alco- 
hol. ${ }^{35}$ Use of medications should be minimized and limited to those known to be safe for patients with porphyria. Table 2 lists some of the medications reported to precipitate attacks of acute porphyria, as well as certain other medications that are considered to present an increased risk of inducing heme precursors. The table represents only a sample of the available information, and updated sources should be consulted whenever questions arise involving the safety of any particular medication, because information about the use of medications in porphyria changes frequently as new information becomes available. Periods of fasting or restricted carbohydrate intake should be avoided. Patients with variegate porphyria and hereditary coproporphyria should avoid sunlight and use appropriate topical sunscreens to prevent the photosensitivity that occurs with these forms of porphyria. ${ }^{6}$ Future treatments of porphyria undoubtedly will include correction of the biochemical defect, and initial steps toward gene therapy have already recently been taken. Namely, porphobilinogen deaminase can be expressed in human acute intermittent porphyria fibroblasts, and nonviral gene delivery of plasmids encoding porphobilinogen deaminase induced synthesis of protoporphyrin in porphobilinogen deaminase-deficient human and mouse cells. ${ }^{39}$

The authors thank Dr. Eric J. Sorensen, who contributed material used in this review.

Disclosure: The authors have at times received honoraria for presentations involving topics discussed in this article. Support of these activities has included both personal and institutional remuneration.

\section{REFERENCES}

1. Adams A. Update on porphyria. Blood line. Acute porphyria. Drug information. http://www.dotpharmacy.com/uporphy. html

2. Albers JW. Porphyric neuropathy. In: Mendell JR, Kissel JT, Cornblath DR, editors. Diagnosis and management of peripheral nerve disorders. New York: Oxford University Press; 2001. p 344-366.

3. Albers JW, Robertson WC Jr, Daube JR. Electrodiagnostic findings in acute porphyric neuropathy. Muscle Nerve 1978; 1:292-296.

4. American Porphyria Foundation. About porphyria. Drugs and porphyria. Drugs considered unsafe and safe in acute porphyrias. www.porphyriafoundation.com.

5. Anonymous. Case records of the Massachusetts General Hospital. Weekly clinicopathological exercises. Case 39-1984. A 29-year-old woman with abdominal pain, myalgia, and muscle weakness. N Engl J Med 1984;311:839-847.

6. Badminton MN, Elder GH. Management of acute and cutaneous porphyrias. Int J Clin Pract 2002;56:272-278.

7. Becker DM, Kramer S. The neurological manifestations of porphyria: a review. Medicine (Baltimore) 1977;56:411-423.

8. Bissell DM. Disorders of porphyrins or metals. Porphyria. In: Wyngaarden JB, Smith LH, editors. Cecil textbook of medicine. Philadelphia: Saunders; 1985. p 1153-1158.
9. Bonkovsky HLB. The porphyrias. Curr Treat Options Gastroenterol 2000;3:487-500.

10. Bonkowsky HL, Tschudy DP, Collins A, Doherty J, Bossenmaier I, Cardinal R, Watson CJ. Repression of the overproduction of porphyrin precursors in acute intermittent porphyria by intravenous infusions of hematin. Proc Natl Acad Sci USA 1971;68:2725-2729.

11. Cacheux V, Martasek P, Fougerousse F, Delfau MH, Druart L, Tachdjian G, Grandchamp B. Localization of the human coproporphyrinogen oxidase gene to chromosome band 3q12. Hum Genet 1994;94:557-559.

12. Day RS, Eales L, Meissner D. Coexistent variegate porphyria and porphyria cutanea tarda. N Engl J Med 1982;307:36-41.

13. Dean G. The porphyrias. A story of inheritance and environment. Bristol, UK: Pitman Medical; 1971.

14. Delfau MH, Picat C, de Rooij FW, Hamer K, Bogard M, Wilson JH, Deybach JC, Nordmann Y, Grandchamp B. Two different point $\mathrm{G}$ to $\mathrm{A}$ mutations in exon 10 of the porphobilinogen deaminase gene are responsible for acute intermittent porphyria. J Clin Invest 1990;86:1511-1516.

15. Delfau-Larue MH, Martasek P, Grandchamp B. Coproporphyrinogen oxidase: gene organization and description of a mutation leading to exon 6 skipping. Hum Mol Genet 1994;3: $1325-1330$

16. Denny-Brown D, Sciarra D. Changes in the nervous system in acute porphyria. Brain 1945;68:1-16.

17. Desnick RJ, Astrin KH, Anderson KE. Inherited porphyrias. In: Rimoin DL, Connor JM, Pyeritz R, Korf BR, editors. Emery and Rimoin's principles and practice of medical genetics. New York: Churchill Livingstone; 2002. p 2587-2623.

18. Devlin TM. Textbook of biochemistry: with clinical correlations. New York: John Wiley \& Sons; 1986.

19. Deybach JC, Puy H, Robreau AM, Lamoril J, Da Silva V, Grandchamp B, Nordmann Y. Mutations in the protoporphyrinogen oxidase gene in patients with variegate porphyria. Hum Mol Genet 1996;5:407-410.

20. Dhar GJ, Bossenmaier I, Petryka ZJ, Cardinal R, Watson CJ. Effects of hematin in hepatic porphyria. Further studies. Ann Intern Med 1975;83:20-30.

21. Dobrschansky M. Einiges über malonal. Wien Med Presse 1906;47:2145-2151.

22. Doss MO. Porphyrinurias and occupational disease. Ann NY Acad Sci 1987;514:204-218.

23. Downey D. Porphyrin enzyme analysis in an oral pathology practice: a look back over four years. Med Hypotheses 1996; 46:563-567.

24. Eales L, Day RS, Blekkenhorst GH. The clinical and biochemical features of variegate porphyria: an analysis of 300 cases studied at Groote Schuur Hospital, Cape Town. Int J Biochem 1980;12:837-853.

25. Elder $G$ and Welsh Medicines Information Center. Acute porphyrias. Drugs that are considered to be safe for use in the acute porphyrias. www.ukmi.nhs.uk.

26. Ellefson RD. Porphyrinogens, porphyrins, and the porphyrias. Mayo Clin Proc 1982;57:454-458.

27. Ellefson RD, Ford RE. The porphyrias: characteristics and laboratory tests. Regul Toxicol Pharmacol 1996;24(suppl): S119-S125.

28. Flugel KA, Druschky KF. Electromyogram and nerve conduction in patients with acute intermittent porphyria. J Neurol 1977;214:267-279.

29. Goldberg A, Rimington C. Diseases of porphyrin metabolism. Springfield, IL: Thomas; 1962.

30. Goren MB, Chen C. Acute intermittent porphyria with atypical neuropathy. South Med J 1991;84:668-669.

31. Grandchamp B, Lamoril J, Puy H. Molecular abnormalities of coproporphyrinogen oxidase in patients with hereditary coproporphyria. J Bioenerg Biomembr 1995;27:215-219.

32. Grandchamp B, Picat C, de Rooij F, Beaumont C, Wilson P, Deybach JC, Nordmann Y. A point mutation $\mathrm{G} \rightarrow \mathrm{A}$ in exon 12 of the porphobilinogen deaminase gene results in exon skip- 
ping and is responsible for acute intermittent porphyria. Nucl Acids Res 1989;17:6637-6649.

33. Grandchamp B, Picat C, Kauppinen R, Mignotte V, Peltonen L, Mustajoki P, Romeo PH, Goossens M, Nordmann Y. Molecular analysis of acute intermittent porphyria in a Finnish family with normal erythrocyte porphobilinogen deaminase. Eur J Clin Invest 1989;19:415-418.

34. Grandchamp B, Picat C, Mignotte V, Wilson JH, Te VK, Sandkuyl L, Romeo PH, Goossens M, Nordmann Y. Tissuespecific splicing mutation in acute intermittent porphyria. Proc Natl Acad Sci USA 1989;86:661-664.

35. Gross U, Hoffmann GF, Doss MO. Erythropoietic and hepatic porphyrias. J Inherit Metabol Dis 2000;23:641-661.

36. Günther H. Die hämatoporphyrie. Archiv Klin Med 1911;105: 89-146.

37. Hierons R. Acute intermittent porphyria. Postgrad Med J 1967;43:605-608.

38. Ishida N, Fujita H, Noguchi T, Doss M, Kappas A, Sassa S. Message amplification phenotyping of an inherited deltaaminolevulinate dehydratase deficiency in a family with acute hepatic porphyria. Biochem Biophys Res Commun 1990;172: 237-242.

39. Johansson AMl. Correction of the biochemical defect in porphobilinogen deaminase deficient cells by non-viral gene delivery. Mol Cell Biochem 2003;250:65-71.

40. Juknat AA, Kotler ML, Quaglino A, Carrillo NM, Hevor T. Necrotic cell death induced by delta-aminolevulinic acid in mouse astrocytes. Protective role of melatonin and other antioxidants. J Pineal Res 2003;35:1-11.

41. Kappas A, Sassa S, Galbraith RA, Nordmann Y. The porphyrias. In: Scriver CR, Beaudet AL, Sly WS, Valle D, editors. The metabolic basis of inherited disease. New York: McGraw-Hill; 1989. p 1305-1365.

42. Kauppinen R, Mustajoki S, Pihlaja H, Peltonen L, Mustajoki P. Acute intermittent porphyria in Finland: 19 mutations in the porphobilinogen deaminase gene. Hum Mol Genet 1995; 4:215-222.

43. Kirsch RE, Meissner PN, Hift RJ. Variegate porphyria. Sem Liver Dis 1998;18:33-41.

44. Lai CW, Hung TP, Lin WS. Blindness of cerebral origin in acute intermittent porphyria. Report of a case and postmortem examination. Arch Neurol 1977;34:310-312.

45. Laiwah AC, Macphee GJ, Boyle P, Moore MR, Goldberg A. Autonomic neuropathy in acute intermittent porphyria. J Neurol Neurosurg Psychiatry 1985;48:1025-1030.

46. Laiwah AC, McColl KE. Management of attacks of acute porphyria. Drugs 1987;34:604-616.

47. Lamon JM, Frykholm BC, Hess RA, Tschudy DP. Hematin therapy for acute porphyria. Medicine (Baltimore) 1979;58: 252-269.

48. Lamoril J, Martasek P, Deybach JC, Da S, V, Grandchamp B, Nordmann Y. A molecular defect in coproporphyrinogen oxidase gene causing harderoporphyria, a variant form of hereditary coproporphyria. Hum Mol Genet 1995;4:275-278.

49. Leger JM, Salachas F. Diagnosis of motor neuropathy. Eur J Neurol 2001;8:201-208.

50. Loftus LS, Arnold WN. Vincent van Gogh's illness: acute intermittent porphyria? BMJ 1991;303:1589-1591

51. MacAlpine I, Hunter R. The "insanity" of King George III: a classic case of porphyria. Br Med J 1966;5479:65-71.

52. MacAlpine I, Hunter R, Rimington C. Porphyria in the royal houses of Stuart, Hanover, and Prussia. A follow-up study of George III's illness. Br Med J 1968;1:7-18.

53. MacAlpine I, Hunter R, Rimington C. Royal malady. Br Med J 1968;1:705-706.

54. Martasek P, Camadro JM, Delfau-Larue MH, Dumas JB, Montagne JJ, de Verneuil H, Labbe P, Grandchamp B. Molecular cloning, sequencing, and functional expression of a cDNA encoding human coproporphyrinogen oxidase. Proc Natl Acad Sci USA 1994;91:3024-3028.

55. Martasek P, Nordmann Y, Grandchamp B. Homozygous hereditary coproporphyria caused by an arginine to tryptophane substitution in coproporphyrinogen oxidase and common intragenic polymorphisms. Hum Mol Genet 1994;3:477-480.

56. Maytham DV, Eales L. Electrodiagnostic findings in porphyria. S Afr Med J 1971;45(special issue):99-100.

57. McColl KE, Moore MR, Thompson GG, Goldberg A. Treatment with haematin in acute hepatic porphyria. Q J Med 1981;50:161-174.

58. Meissner PN, Dailey TA, Hift RJ, Ziman M, Corrigall AV, Roberts AG, Meissner DM, Kirsch RE, Dailey HA. A R59W mutation in human protoporphyrinogen oxidase results in decreased enzyme activity and is prevalent in South Africans with variegate porphyria. Nat Genet 1996;13:95-97.

59. Meissner PN, Day RS, Moore MR, Disler PB, Harley E. Protoporphyrinogen oxidase and porphobilinogen deaminase in variegate porphyria. Eur J Clin Invest 1986;16:257-261.

60. Mever UA, Strand LJ, Doss M, Marver HS. Intermittent acute porphyria-demonstration of a genetic defect in porphyrine metabolism. N Engl J Med 1972;286:1277-1282.

61. Moore MR, McColl KE. Therapy of the acute porphyrias. Clin Biochem 1989;22:181-188.

62. Moore MR, McColl KEL, Rimington C, Goldberg SA. Disorders of porphyrin metabolism. New York: Plenum; 1987. p. $18-155$.

63. Mustajoki P. Red cell uroporphyrinogen I synthetase in acute intermittent porphyria. Ann Clin Res 1976;8(suppl 17):133138.

64. Nagler W. Peripheral neuropathy in acute intermittent porphyrias. Arch Phys Med Rehabil 1971;52:426-431.

65. Nordmann Y, de Verneuil H, Deybach JC, Delfau MH, Grandchamp B. Molecular genetics of porphyrias. Ann Med 1990; 22:387-391.

66. Nordmann Y, Puy H. Human hereditary hepatic porphyrias. Clin Chim Acta 2002;325:17-37.

67. Parera VED. Acute porphyrias in the Argentinean population: a review. Cell Mol Biol 2003;-49:493-500.

68. Paterniti JR Jr, Simone IJ, Beattie DS. Detection and regulation of delta-aminolevulinic acid synthetase activity in the rat brain. Arch Biochem Biophys 1978;189:86-91.

69. Percy VA, Shanley BC. Prophyrin precursors in blood, urine and cerebrospinal fluid in acute porphyria. S Afr Med J 1977;52:219-222.

70. Percy VA, Shanley BC. Studies on haem biosynthesis in rat brain. J Neurochem 1979;33:1267-1274

71. Pierach CA. Hematin therapy for the porphyric attack. Semin Liver Dis 1982;2:125-131.

72. Pierach CA, Weimer MK, Cardinal RA, Bossenmaier IC, Bloomer JR, Blommer JR. Red blood cell porphobilinogen deaminase in the evaluation of acute intermittent porphyria. JAMA 1987;257:60-61.

73. Potluri VR, Astrin KH, Wetmur JG, Bishop DF, Desnick RJ. Human delta-aminolevulinate dehydratase: chromosomal localization to $9 \mathrm{q} 34$ by in situ hybridization. Hum Genet 1987; 76:236-239.

74. Ranking JE, Pardington GL. Two cases of haemato-porphyria in the urine. Lancet 1890;2:607-609.

75. Ridley A. The neuropathy of acute intermittent porphyria. Q J Med 1969;28:307-333.

76. Ridley A. Porphyric neuropathy. In: Dyck PJ, Thomas PK, Lambert EH, Bunge R, editors. Peripheral neuropathy. Philadelphia: Saunders; 1984. p 1704-1716.

77. Roberts AG, Whatley SD, Daniels J, Holmans P, Fenton I, Owen MJ, Thompson P, Long C, Elder GH. Partial characterization and assignment of the gene for protoporphyrinogen oxidase and variegate porphyria to human chromosome 1q23. Hum Mol Genet 1995;4:2387-2390.

78. Sack GH Jr. Acute intermittent porphyria. JAMA 1990;264: $1290-1293$

79. Santosh PJ, Malhotra S. Varied psychiatric manifestations of acute intermittent porphyria. Biol Psychiatry 1994;36:744747

80. Sassa S, Kappas A. Prenatal diagnosis of acute intermittent porphyria. N Engl J Med 1976;295:1381. 
81. Sassa S, Kappas A. Molecular aspects of the inherited porphyrias. J Intern Med 2000;247:169-178.

82. Schreiber WE. A molecular view of the neurologic porphyrias. Clin Lab Med 1997;17:73-83.

83. Schreiber WE, Fong F, Nassar BA, Jamani A. Heteroduplex analysis detects frameshift and point mutations in patients with acute intermittent porphyria. Hum Genet 1995;96:161166.

84. Schreiber WE, Jamani A, Armstrong JG. Acute intermittent porphyria in a native North American family. Biochemical and molecular analysis. Am J Clin Pathol 1995;103:730-734.

85. Schreiber WE, Zhang X, Senz J, Jamani A. Hereditary coproporphyria: exon screening by heteroduplex analysis detects three novel mutations in the coproporphyrinogen oxidase gene. Hum Mutat 1997;10:196-200.

86. Scobie GA, Llewellyn DH, Urquhart AJ, Smyth SJ, Kalsheker NA, Harrison PR, Elder GH. Acute intermittent porphyria caused by a C-T mutation that produces a stop codon in the porphobilinogen deaminase gene. Hum Genet 1990;85:631634.

87. Scott L, Bean DW. Psychiatric manifestations of porphyria. S Dakota J Med 1987;40:5-8

88. Sorensen AWS, With TK. Persistent paresis after prophyric attacks. S Afr Med J 1971;45(special issue):101-103.

89. Sorenson EJ, Albers JW. Neurological manifestations of porphyria. In: Goetz CG, Aminoff MJ, editors. Handbook of clinical neurology, vol. 70. Amsterdam: Elsevier; 1998. p 299312.

90. Stein JA, Tschudy DP. Acute intermittent porphyria. A clinical and biochemical study of 46 patients. Medicine (Baltimore) 1970;49:1-16.
91. Stewart PM, Hersley WJ. An acute attack of variegate porphyria complicated by severe autonomic neuropathy. Aust NZ J Med 1981;11:82-83.

92. Taketani S, Inazawa J, Abe T, Furukawa T, Kohno H, Tokunaga R, Nishimura K, Inokuchi H. The human protoporphyrinogen oxidase gene (PPOX): organization and location to chromosome 1. Genomics 1995;29:698-703.

93. The Guillain-Barré syndrome study group. Plasmapheresis and acute Guillain-Barré syndrome. Neurology 1985;35:1096-1104.

94. Thunell S, Holmberg L, Lundgren J. Aminolaevulinate dehydratase porphyria in infancy. A clinical and biochemical study. J Clin Chem Clin Biochem 1987;25:5-14.

95. Wang AL, Arredondo-Vega FX, Giampietro PF, Smith M, Anderson WF, Desnick RJ. Regional gene assignment of human porphobilinogen deaminase and esterase A4 to chromosome 11q23 leads to 11qter. Proc Natl Acad Sci USA 1981;78: $5734-5738$.

96. Warnich L, Kotze MJ, Groenewald IM, Groenewald JZ, van Brakel MG, van Heerden CJ, de Villiers JN, van de Ven WJ, Schoenmakers EF, Taketani S, Retief AE. Identification of three mutations and associated haplotypes in the protoporphyrinogen oxidase gene in South African families with variegate porphyria. Hum Mol Genet 1996;5:981-984.

97. Windebank AJ, Bonkovsky HL. Porphyric neuropathy. In: Dyck PJ, Thomas PK, Griffin JW, Low PA, Poduslo JF, editors. Peripheral neuropathy. Philadelphia: Saunders; 1993. p 1161-1168.

98. Yeung Laiwah AC, Moore MR, Goldberg A. Pathogenesis of acute porphyria. QJ Med 1987;63:377-392.

99. Zimmerman EA, Lovelace RE. The etiology of the neuropathy in acute intermittent porphyria. Trans Am Neurol Assoc 1968; 93:294-296. 